\section{Sad time for salmon}

International Atlantic Salmon Symposium. Edited by Morden W. Smith and Wilfred M. Carter. Pp. xi+504. (Atlantic Salmon Research Trust: Fanham, Surrey; International Atlantic Salmon Foundation; New Brunswick, 1973.) £6.50 boards; £5 paper.

THrs collection of papers is the published proceedings of the "Symposium on the Atlantic Salmon: the Management, Biology and Survival of the Species", held at the Huntsman Marine Laboratory, St Andrews, New Brunswick, in September 1972. It consists of thirty-one major contributions under six main headings; the effects of man and the changing environment, physiology, ecology, aquaculture, environmental engineering and fishery economics, and conservation and fisheries.

With such a wide-ranging approach to the problems which surround the Atlantic salmon it is not surprising that several of the papers seem to have little direct relevance to the main objects of the symposium. One contribution invokes the aid of systems analysis for salmon conservation in a dauntingly titled paper, "the FASTRR concept (Facility for Atlantic Salmon Technological Research and Restoration). A status report". This concludes "the design and construction of an improved intensive culture hatchery depends on the determination of biological and physical needs, their estimated implementation and operating costs as balanced against predicted benefit to the overall project objectives. Elements of this study hopefully will ease the decision maker's task of quantitative initial assessment, choosing between alternates, and managing efficiently...". (One wonders what Frank Buckland, Inspector of Salmon Fisheries, 1867-1879, who managed to hatch salmon and trout eggs in the kitchen of his home in Albany Street, London, would have said of that?)

The salmon, in an unique way, is the focus of emotional attitudes. As an economic, leisure, or food resource it is probably without equal, but its decline in the industrialised and heavily populated North Atlantic countries has been quite dramatic. Reaction to dwindling salmon stocks in many countries suggests that although this may be more or less acceptable, it is clearly not acceptable for other nations to exploit the stocks outwith the national boundaries. Thus, the relatively recently developed high-seas fisheries conducted off the coast of West Greenland, and also in the Norwegian Sea, has resulted in a crisis within the salmon-producing countries, made still more emotional by the fact that the country mainly operating the fishery is not a salmon producer. This development has placed the conservation of the Atlantic salmon firmly in the field of international relations, and as Dr Wilfrid M. Carter, co-editor of this volume, remarks, "the Atlantic salmon, perhaps more than any other fish has become symptomatic of the unwillingness of the international community to face and to solve critical problems..."

The contributions in this volume essentially fall into three categories (although they are not so divided by the organisers): the biological papers, some of which have direct relevance to the conservation of the species, papers on the management of stocks, and those directly related to the international management of the species. This last category would seem to have the most direct bearing on the major problem confronting the salmon. In this context, the review by B. B. Parrish of the work on the ICES/ ICNAF Joint Working Party on the North Atlantic Salmon is a major contribution, summarising the problems involved and distinguishing the areas of biological knowledge that require to be clarified before more precise assessments of their effects can be made. But as D. L. McKernan points out elsewhere in the volume, the adoption of an ICNAF formula to phase out the non-native high seas fishery off Greenland, and to impose a catch limit on the inshore fishery, offers reason to be cautiously optimistic for the future of the Atlantic salmon. Alwyne WheEler

\section{Weather forecast}

Radar Observation of the Atmosphere. By L. J. Battan. Pp. $x+324$. (University of Chicago: Chicago and London, 1973.) £7.15.

THERE has been a considerable increase during the past two decades in the use of electronic techniques for the remote sensing of the atmosphere, with radar playing an important if not dominant part. So much new material had become available that the author has carried out an extensive revision of his earlier work Radar Meteorology, first published in 1959. The present volume under its new title is solely concerned with the application of microwave radar in the study of atmospheric phenomena including precipitation, cloud, wind and clear air turbulence. The author has succeeded in covering most of the relevant material in less than 300 pages of text. This should have considerable appeal to a wide scientific readership apart from meteorologists, particularly those who lack a specific background in electronics.
The principles of radar are well illustrated although the author's very brief introduction concerning the properties of electromagnetic waves will hardly benefit a reader who is not already familiar with the subject. The remainder of the book deals with radar applications and the related atmospheric physics in appreciable depth. Although space may have been limited it would have been attractive if the author had covered in the same manner some aspects of upper atmospheric work including chaff and meteor radar as well as incoherent scatter techniques. Numerous technical details of radar installations are given in an appendix and readers will welcome a very comprehensive and up to date list of references. H. G. MuLleR

\section{Strange coincidence}

The Challenge of Chance: Experiments and Speculations. By Alister Hardy, Robert Harvie and Arthur Koestler. Pp. 280. (Hutchinson: London, November 1973.) $£ 3$.

DURING a recent visit to America I was met at Roanoke Airport by my friend the statistician, I. J. Good, of the Virginia Polytechnic. Good excitedly asked me what type of plane I had flown in on and when I told him a Boeing 727 he cried "I knew it. I knew it". He then pointed to the licence plate of his Ford Mustang, which boldy featured the inscription "CRE 727". Permanent testimony to the happy correspondence between my initials, the plane $I$ had flown in and Jack Good's car exists in the form of a licence plate which now adorns my office wall.

If you like stories of this kind you will revel in Challenge of Chance, which is described on the blurb as being "the first book to be written jointly by a Fellow of the Royal Society and a Fellow of the Royal Society of Literature-with a psychologist providing the bridge between the two cultures". The interdisciplinary flavour of the work is certainly striking, but the bridge is rather a shaky one. The book falls uneasily into three separate chunks-the first an account by Sir Alister of an "unsuccessful" mass extra-sensory perception experiment, the second a thirty page dicussion by Harvie of probability theory and how puzzling it all is; the third a long essay by Koestler on some of the strange things that have happened to him, his friends and his correspondents. The majority of the strange things, I hasten to add, are somewhat more marvellous than the CRE 727 example. Hardy's experiment incidentally - a group ESP test in the Caxton Hall-was only unsuocessful in that no evidence of 